УДК 616-001-097.1/.3

DOI: $10.26435 /$ UC.V0I3(36).503

\author{
Ю.И. Стрельченко, В.Н. Ельский
}

ГОО ВПО «Донецкий национальный медицинский университет имени М. Горького», Донецк

\title{
МЕТААНАЛИЗ ИММУНОЛОГИЧЕСКИХ И МИКРОБИОЛОГИЧЕСКИХ ПОКАЗАТЕЛЕЙ ПРИ ТРАВМАТИЧЕСКОЙ БОЛЕЗНИ
}

По данным Всемирной организации здравоохранения травматизм продолжает лидировать по причине инвалидизации и смертности у лиц молодого, трудоспособного возраста [1]. В то же время во многих странах к производственному травматизму присоединяются случаи военной травмы, в том числе и в Донецкой Народной Республике, Украине, Российской Федерации [2].

Математический анализ исследований, выполненных 30-40 лет назад, проводился на так называемых электронно-вычислительных машинах, которые по своей мощности и функциональности слабо отличаются от современных обычных калькуляторов. Адекватное программное обеспечение для статистической обработки данных (Statistica, MedStat) начало появляться всего лишь 20 лет назад. Поэтому в свете современной доказательной медицины отдаются предпочтения так называемому метаанализу [3], который позволяет пересмотреть данные исследований за большой период времени и выборок различных мощностей, получить новые данные, взаимосвязи, уточнить упущенные и неопубликованные материалы, взглянуть на проблему под другим углом зрения.

\section{ЦЕЛ Ь ИССЛЕДОВАНИЯ}

Провести метаанализ иммунологических и микробиологических показателей при травматической болезни, полученных на кафедре патофизиологии для уточнения ключевых звеньев её патогенеза, которые в последующем смогут явиться прогностическими критериями и целями для таргетной терапии, дать заключение о возможности перенесения экспериментальных данных на организм человека.

\section{МАТЕРИАЛ И МЕТОДЫ}

На кафедре патофизиологии ГОО ВПО ДОННМУ ИМ. М. ГОРКЬОГО за последние 40 лет накопился обширный экспериментальный и отчасти клинический материал по травматической болезни. Это более чем 40 кандидатских и докторских диссертаций, порядка 10 монографий.
Нами были отобраны те работы, в которых проводилось исследование иммунологических и микробиологических показателей (табл. 1.). В них вошло 10 кандидатских диссертаций, три докторских и одна монография, в которых проанализированы показатели 7720 пострадавших и 3907 экспериментальных животных. Особенностью материала, взятого для метаанализа, явилось то, что это не просто опубликованные статьи со вторичными данными, а оригинальные диссертационные исследования (рукописи) с полноценным табличным материалом, который является производным от первичного материала. Это позволило нам не просто сравнить, а заново пересчитать многие показатели, проанализировать мощность и достаточность объёма выборок, корректность математического анализа, получить новые данные, взаимосвязи, осветить упущенные и неопубликованные авторами материалы. В то же время нужно оговориться, что проведенный нами метаанализ ни в коем случае не умаляет значения, и уж тем более не опровергает данные оригинальных авторских исследований, но позволяет, как было сказано выше взглянуть на проблему травматической болезни под другим углом зрения, с высоты прошедших лет (временной параметр) и количества проведенных исследований (объём выборки).

Были проанализированы следующие иммунологические и микробиологические показатели: лейкоцитарная формула (общее количество лейкоцитов, Г/л; палочкоядерные нейтрофилы, \% и Г/л; сегментоядерные нейтрофилы, \% и Г/л; лимфоциты, \% и Г/л, моноциты, \% и Г/л, эозинофилы, \% и Г/л); лимфограмма (CD 3, \% и Г/л; CD 4, \% и Г/л; CD 8, \% и Г/л; CD 16, \% и Г/л; CD 20, \% и Г/л; CD 25, \% и Г/л; CD 95, \% и Г/л; HLA-DR, \% и Г/л; иммунорегуляторный индекс (ИРИ, CD 4 / CD 8), ед.); иммуноглобулины (Ig) основных классов (A, M, G), Г/л; циркулирующие им-

(с) Ю.И. Стрельченко, В.Н. Ельский, 2020

(c) Университетская Клиника, 2020 
Материал, взятый для метаанализа иммунологических и микробиологических показателей

\begin{tabular}{|c|c|c|}
\hline Ф. И. О., год, название & $\begin{array}{c}\text { Модель, количество жи- } \\
\text { вотных или пострадавших }\end{array}$ & Показатели \\
\hline $\begin{array}{l}\text { Крюк Ю. Я., 1995, докт. дисс.: «Патогенез ослож- } \\
\text { нённого течения травматической болезни» }\end{array}$ & $\begin{array}{l}\text { Пострадавшие с различ- } \\
\text { ными видами травм, } 956\end{array}$ & $\begin{array}{c}\text { Лейкограмма, лим- } \\
\text { фограмма, имму- } \\
\text { ноглобулины }\end{array}$ \\
\hline $\begin{array}{l}\text { Жуков Ю. Б., 1997, докт. дисс.: «Хирургиче- } \\
\text { ское и консервативное лечение потерпевших } \\
\text { с повреждениями опорно-двигательной си- } \\
\text { стемы, которые сочетаны с травмой головно- } \\
\text { го мозга в остром периоде травматической бо- } \\
\text { лезни, его патогенетическое обоснование» }\end{array}$ & $\begin{array}{c}\text { Метод Кеннона в моди- } \\
\text { фикации, 30. Постра- } \\
\text { давшие с различны- } \\
\text { ми видами травм, } 435\end{array}$ & $\begin{array}{l}\text { Лейкограмма, лим- } \\
\text { фограмма, иммуно- } \\
\text { глобулины, фагоци- } \\
\text { тоз, микробиологи- } \\
\text { ческие показатели }\end{array}$ \\
\hline $\begin{array}{l}\text { Ельский А. В., 1999, канд. дисс.: «Особен- } \\
\text { ности патогенеза и лечения тяжёлой ме- } \\
\text { ханической травмы у пострадавших в со- } \\
\text { стоянии алкогольной интоксикации» }\end{array}$ & $\begin{array}{l}\text { Пострадавшие с различ- } \\
\text { ными видами травм, } 217\end{array}$ & $\begin{array}{c}\text { Лейкограмма, лим- } \\
\text { фограмма, имму- } \\
\text { ноглобулины }\end{array}$ \\
\hline
\end{tabular}

Золотухин С. Е., 2000, докторская диссертация: «Травматическая болезнь у шахтёров глубоких угольных шахт Донбасса»

Ельский В. Н. и соавт., 2002, монография: «Избранные аспекты патогенеза и лечения травматической болезни»
Пострадавшие с различными видами травм, 3508. Метод Кеннона в модификации, 630. Длительное раздавливание мягких тканей по Ельскому, 232

Метод Кеннона в модификации, 360. Длительное раздавливание мягких тканей по Ельскому, 232. Пострадавшие с различными видами травм, 2467

Крюк А. Ю., 2008, канд. дисс.: «Особенности патогенеза гиперметаболизма в системном воспалительном ответе организма при тяжёлой механической травме» Зенько Н. А., 2011, канд. дисс.: «Особенности нарушений и коррекция кальциевого обмена при черепно-мозговой травме, протекающей на фоне стероидного остеопороза» Битюков Д. С., 2013, канд. дисс.: «Нарушение функции гипоталамо-гипофизарнонадпочечниковой системы и антибактериальной резистентности при гнойновоспалительных осложнениях травматической болезни и их коррекция» Стрельченко Ю. И., 2013, канд. дисс.: «Патогенетические механизмы ожоговой травмы и возможность их коррекции поляризованным светом» Берест Е. Л., 2013, канд. дисс.: «Особенности патогенеза и прогнозирование доминирования повреждений и гнойновоспалительных осложнений при челюстномозговой травме в эксперименте» Нечепорчук А. В., 2018, канд. дисс.: «Особенности оксидативного стресса в зависимости от индивидуальной реактивности организма и его коррекция при черепно-мозговой травме, протекающей на фоне турникетного токсикоза в эксперименте» Юдин В. А., 2018, канд. дисс.: «Особенности иммунологических нарушений и их коррекция в раннем периоде травматической болезни у пострадавших с политравмой голени»

Фабер А. И., 2019, канд. дисс.: «Особенности патогенеза сочетанной черепно-мозговой травмы и обоснование эффективной фармакокоррекции»

Есаулов А. Д., 2019, канд. дисс.: «Особенности нарушения метаболизма при тяжелой механической травме, протекающей на фоне стероидного остеопороза, и принципы ее коррекции»

Метод Кеннона в модификации, 194

Черепно-мозговая травма по Золотухину, 341

Лейкограмма, лимфограмма, иммуноглобулины

Лейкограмма, лимфограмма, иммуноглобулины

Лейкограмма, цитокины, микробиологические показатели

\section{Цитокины}

Лейкограмма, цитоки-

Метод Кеннона в модификации, 384 ны, иммуноглобулины, фагоцитоз, микробиологические показатели

Лейкограмма, лимфограмма, иммуноглобулины, фагоцитоз

Лейкограмма, цитокины, иммуноглобулины, фагоцитоз, микробио-

логические показатели ма по Золотухину, 548

Черепно-мозговая травма по Золотухину. Длительное раздавливание мягких тканей по Ельскому, 254

Лейкограмма, цитокины, иммуноглобулины, фагоцитоз

Пострадавшие с сочетанными травмами, 137

Черепно-мозговая травма по Золотухину, 284

Лейкограмма, лимфограмма, цитокины, иммуноглобулины, фагоцитоз Лейкограмма, цитокины, иммуноглобулины, фагоцитоз, микробиологические показатели

Метод Кеннона в модификации, 148
Лейкограмма, цитокины, микробиологические показатели 
мунные комплексы (ЦИК), ед.; показатели активности фагоцитоза: фагоцитарный индекс (ФИ), \%; фагоцитарное число (ФЧ), ед.; цитокиновый профиль: интерлейкины (IL)- $1 \beta$, IL-2, IL-4, IL-6, IL-8, фактор некроза опухолей альфа (TNF- $\alpha)$, пг / мл; микробные ассоциации, \%; микробные тела, \%; грибковые ассоциации, \%; грибковые тела, \%; частота выявления различных микроорганизмов в крови, \% (грампозитивные и грамнегативные палочки, грампозитивные диплококки, E. coli, E. faecalis, S. epidermidis, S. aureus, N. flavescens, Candidae. sp).

Весь математический анализ проводился с помощью лицензионных программ Microsoft Office Excell (v. 14.0.7237.5000 32-разрядная, номер продукта: 02260-018-0000106-48881, Microsoft Corporation, 2010) и MedStat v. 5.2 (Copyright (c) 2003-2019). Были использованы следующие методы и критерии: расчёт размера выборки для сравнения двух частот, расчёт размера выборки для сравнения двух средних, проверка на нормальность: критерий W Шапиро-Уилка, критерий Д'Агостино-Пирсона, сравнение центральных тенденций для двух несвязанных выборок, $\mathrm{W}$-критерий Вилкоксона, критерий $\chi$-квадрат, ранговый однофакторный анализ КрускалаУоллиса, сравнение доли для двух групп, угловое преобразования Фишера (с учётом поправки Йейтса), стандартная ошибка доли по формуле Бернулли [4].

\section{ДИЗАЙН ИССЛЕДОВАНИЯ}

Иммунологические и микробиологические показатели оценивались в начальном периоде травматической болезни в среднем в течение часа после получения травмы. Это как раз то время, которому уделялось больше всего внимание всеми авторами, так как именно в этот «золотой» промежуток времени ещё можно повлиять на прогноз и исход травматической болезни.

Большинство авторов разделяли животных (пострадавших) на две (некоторые на три) группы, в зависимости от их выживаемости (животных или пострадавших). Мы приняли такую классификацию и также выделили две основные группы: благоприятный исход (неотягощённая травма) и неблагоприятный исход (отягощённая травма).

В диссертациях, в которых было достаточно табличного материала, исходные данные были нами по возможности пересчитаны, для определения достаточности объёма выборки, уточнения полученных авторами статистически значимых различий, получения новых (упущенных) данных, неосвещённых взаимосвязей.
Для проведения сравнения различных исследований между собой абсолютные иммунологические и микробиологические показатели были переведены в удельные по отношению к группе сравнения (контроля) в каждом конкретном исследовании, в каждой серии опытов. Таким образом, оценивалось направление (вектор) и степень отклонения от группы сравнения (контроля), взятой за единицу. А затем вычислялась и оценивалась разница удельных показателей неблагоприятного исхода травмы и благоприятного.

Хочется отметить, что во всех экспериментальных исследованиях методики травматизации были стандартизированы (длительное раздавливание мягких тканей по Ельскому, метод Кеннона в модификации, взрывная шахтная травма с её компонентами по Кривобоку и черепно-мозговая травма по Золотухину) и направлены на развитие трёх типов посттравматических реакций: шоковой смертельной, шоковой несмертельной и нешоковой.

\section{РЕЗУЛЬТАТЫ И ОБСУЖДЕНИЕ}

При анализе иммунологических показателей последствий травмы, были получены следующие обобщённые данные у животных с благоприятным исходом (неотягощённая травма) и неблагоприятным исходом (отягощённая травма). Как мы видим из таблицы 2, у животных с благоприятным исходом травмы, все показатели, кроме Ig М, статистически значимо отличались от контрольных цифр (p<0,001). Наибольшие изменения отмечались по показателям палочкоядерных и сегментоядерных нейтрофилов, которые были выше группы контроля на $258 \%$ и $110 \%$ соответственно, p<0,001. Имела место прогнозируемая перераспределительная (миграционная) эозинопения, а также стрессовая лимфопения на уровне Т-клеточного звена и умеренный лимфоцитоз (на 53\%) на уровне В-клеточного звена. Всё это сопровождалось выраженной гиперцитокинемией, уровень которых превышал контрольные цифры в 2-3 раза, a IL-6, IL-8 и TNF- $\alpha$ в 8,$5 ; 14,9$ и 6,24 раза соответственно, p<0,001. Всё вышесказанное является неспецифической стресс-реакцией организма на полученную травму и вписывается в известный патогенез травматической болезни.

у животных с неблагоприятным исходом травмы, абсолютно все показатели статистически значимо отличались от контрольных цифр $(\mathrm{p}<0,001)$. Наибольшие изменения отмечались по показателям палочкоядерных и сегментоядерных нейтрофилов, которые были выше группы контроля на $785 \%$ и $256 \%$ соответственно, p<0,001. Имела место выраженная эозинопе- 
Обобщённые иммунологические и микробиологические показатели у животных

Таблица 2.

с различными исходами травмы (удельные величины к группе контроля, p<0,001)

\begin{tabular}{|c|c|c|c|}
\hline Показатель & Благоприятный исход & Неблагоприятный исход & $\Delta$ \\
\hline Общее количество лейкоцитов & 1,72 & 2,63 & $\uparrow+0,905$ \\
\hline Нейтрофилы п / я & 3,58 & 8,85 & $\uparrow+5,27$ \\
\hline Нейтрофилы с / я & 2,10 & 3,56 & $\uparrow+1,46$ \\
\hline Эозинофилы & 0,800 & 0,130 & $\downarrow-0,671$ \\
\hline Лимфоциты & 1,48 & 1,61 & $\uparrow+0,135$ \\
\hline Моноциты & 1,38 & 1,25 & $\downarrow-0,137$ \\
\hline CD 3 & 0,839 & 0,729 & $\downarrow-0,110$ \\
\hline $\mathrm{CD} 4$ & 0,891 & 0,764 & $\downarrow-0,127$ \\
\hline $\mathrm{CD} 8$ & 0,710 & 0,417 & $\downarrow-0,293$ \\
\hline CD 16 & 0,931 & 0,637 & $\downarrow-0,294$ \\
\hline CD 20 & 1,53 & 1,15 & $\downarrow-0,380$ \\
\hline ИРИ (CD 4 / CD 8) & 1,32 & 2,32 & $\uparrow+1,00$ \\
\hline IL-1 $1 \beta$ & 2,14 & 4,14 & $\uparrow+1,99$ \\
\hline IL-2 & 3,24 & 5,51 & $\uparrow+2,27$ \\
\hline IL-4 & 1,86 & 2,33 & $\uparrow+0,468$ \\
\hline IL-6 & 8,50 & 21,5 & $\uparrow+13,0$ \\
\hline IL-8 & 14,9 & 30,5 & $\uparrow+15,6$ \\
\hline TNF- $\alpha$ & 6,24 & 14,7 & $\uparrow+8,51$ \\
\hline Ig A & 1,06 & 0,982 & $\downarrow-0,078$ \\
\hline Ig M & 1,$00 ; p>0,05$ & 0,969 & $\downarrow-0,033$ \\
\hline $\operatorname{Ig} G$ & 0,984 & 0,897 & $\downarrow-0,086$ \\
\hline ФИ & 0,792 & 0,920 & $\uparrow+0,128$ \\
\hline$\Phi Ч$ & 1,18 & 1,12 & $\downarrow-0,056$ \\
\hline ЦИК & 1,22 & 2,37 & $\uparrow+1,15$ \\
\hline
\end{tabular}

ния, а также стрессовая лимфопения на уровне Т-клеточного звена и невыраженный лимфоцитоз (на 15\%, p<0,001) на уровне В-клеточного звена. Обращает на себя внимание резкий сдвиг в сторону увеличения иммунорегуляторного индекса в 2,32 раза, что свидетельствует о резком рекрутировании хелперов и гиперреактивном характере ответа. Всё это сопровождалось запредельной гиперцитокинемией, уровень которых превышал контрольные цифры уже в 4-5 ра3, а IL-6, IL-8 и TNF- $\alpha$ в 21,5; 30,5 и 14,7 раз соответственно, $\mathrm{p}<0,001$.

Как мы видим на рисунке 1 , между неблагоприятным и благоприятным исходом травмы наименьшие различия отмечались по показателям фагоцитарного числа $(-0,056), \operatorname{Ig} \mathrm{M}(-0,033)$ и IL-4 $(+0,468), \mathrm{p}<0,001$. Это может быть объяс- нено двояко. Первое, эти показатели являются малосущественными в патогенезе отягощения и декомпенсации течения травматической болезни и на них, возможно, не стоит обращать особого внимания при прогнозировании исхода и выборе тактики лечения таких пострадавших. Второе, эти показатели являются жёсткими константами организма (что маловероятно) и их несущественные отклонения компенсируются комплексом иных показателей организма. Второе утверждение применимо для производных показателей, например, таких как артериальное давление или минутной объём крови, которые мы разбирали в нашей предыдущей статье. В данном случае, это, скорее всего, является случайной находкой исследования. Чего нельзя сказать о показателях палочкоядерного нейтро- 
филёза (выше на 527\%) и запредельной гиперцитокинемии по уровню TNF- $\alpha$ (выше на 851\%), IL-6 (выше на 1 300\%) и IL-8 (выше на 1 560\%), $\mathrm{p}<0,001$. Данные результаты можно рассматривать в качестве начала развития синдрома системного воспалительного ответа (CCBO, system inflammatory response syndrome, SIRS). Что может иметь существенное прогностическое и терапевтическое значение.

При анализе микробиологических показателей (рис. 2.) при неблагоприятном исходе травмы обнаружена патологическая транслокация энтеробактерий и грибов Candidae sp. из кишечника, а также из слизистых дыхательного тракта (микрококки, стафилококки, нейссерии). Это подтверждает гипотезу о развитии ССВО, а также о срыве гистогематических барьеров при отягощённой травме. Данные микробиологические показатели могут иметь прогностическое и терапевтическое значение.

При анализе иммунологических показателей последствий травмы, у пострадавших с благоприятным исходом (неотягощённая травма) и неблагоприятным исходом (отягощённая травма) были получены обобщённые данные, представленные в таблице 3. У пострадавших с благоприятным исходом травмы, также как и у животных, все показатели статистически значимо отличались от контрольных цифр $(\mathrm{p}<0,001)$. Наибольшие изменения отмечались по показателям палочкоядерных и сегментоядерных нейтрофилов, которые были выше группы контроля на $429 \%$ и $104 \%$ соответственно, p<0,001. Имела место прогнозируемая перераспределительная (миграционная) эозинопения, а также стрессовая лимфопения на уровне Т-и В-клеточного звена и минимальный лимфоцитоз (на 21\%, $\mathrm{p}<0,001)$ на уровне регуляторного звена (CD 8), что сдвинуло иммунорегуляторный индекс в сторону уменьшения $(0,56)$. Всё это сопровождалось выраженной гиперцитокинемией, уровень которых превышал контрольные цифры в 3-4 раза, а IL-6, IL-8 и IL-10 в 8,$65 ; 5,16$ и 17,4 раза соответственно, $\mathrm{p}<0,001$. Всё вышесказанное также является неспецифической стресс-реакцией организма на полученную травму и вписывается в известный патогенез травматической болезни.

У пострадавших с неблагоприятным исходом травмы также все показатели статистически значимо отличались от контрольных цифр $(\mathrm{p}<0,001)$. Наибольшие изменения отмечались по показателям палочкоядерных и сегментоядерных нейтрофилов, которые были выше группы контроля на $692 \%$ и $329 \%$ соответственно, $\mathrm{p}<0,001$. Имела место выраженная эозинопения, а также стрессовая лимфопения на уровне
Т-и В-клеточного звена и минимальный лимфоцитоз (на $50 \%, \mathrm{p}<0,001)$ на уровне регуляторного звена (CD 8), что сдвинуло иммунорегуляторный индекс в сторону уменьшения $(0,587)$. Всё это сопровождалось запредельной гиперцитокинемией, уровень которых превышал контрольные цифры уже в 2-6 ра3, a IL-6 и IL-10 в 12,7 и 13,4 раз соответственно, $\mathrm{p}<0,001$.

Как мы видим на рисунке 3, между неблагоприятным и благоприятным исходом травмы наименьшие различия отмечались по показателям CD $4(-0,056 ; \mathrm{p}<0,001)$, фагоцитарного индекса $(-0,014 ; \mathrm{p}>0,05)$ и иммунорегуляторного индекса $(+0,027 ; p>0,05)$,. Это может быть объяснено двояко. Первое, эти показатели являются малосущественными в патогенезе отягощения и декомпенсации течения травматической болезни и на них, возможно, не стоит обращать

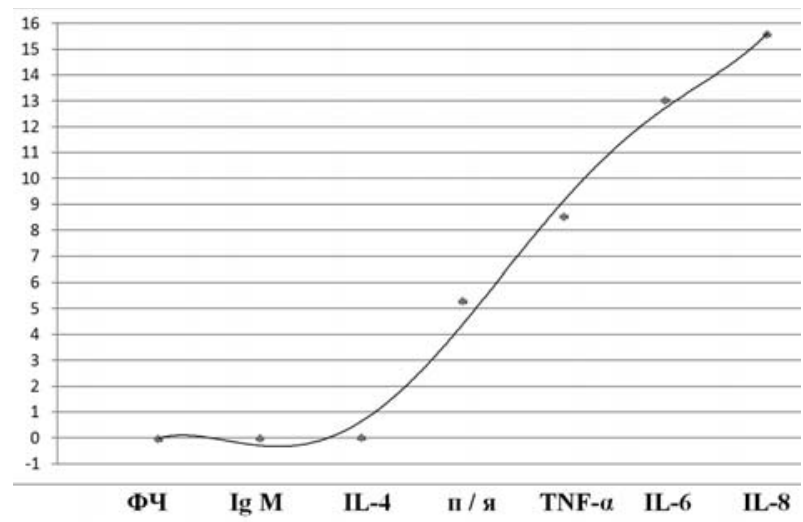

Рис. 1. Разница обобщённых иммунологических показателей животных с неблагоприятным исходом травмы от животных с благоприятным исходом (принята за ноль)

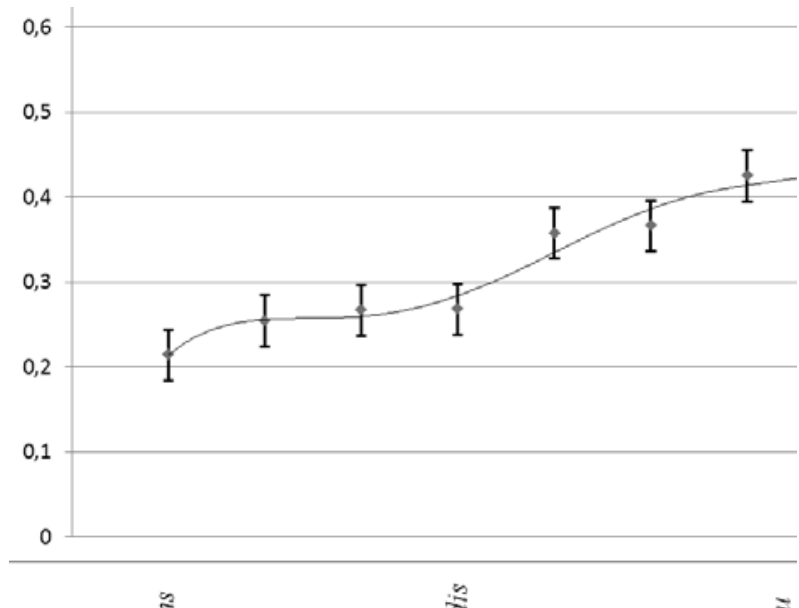

Рис. 2. Разница обобщённых микробиологических показателей животных с неблагоприятным исходом травмы от животных с благоприятным исходом (принята за ноль, $\mathrm{p}<0,001)$ 
Таблица 3.

Обобщённые иммунологические и микробиологические показатели у пострадавших с различными исходами травмы (удельные величины к группе контроля, p<0,001)

\begin{tabular}{|c|c|c|c|}
\hline Показатель & Благоприятный исход & Неблагоприятный исход & $\Delta$ \\
\hline Общее количество лейкоцитов & 2,24 & 3,30 & $\uparrow+1,06$ \\
\hline Нейтрофилы п / я & 5,29 & 7,92 & $\uparrow+2,63$ \\
\hline Нейтрофилы с / я & 2,04 & 4,29 & $\uparrow+2,25$ \\
\hline Эозинофилы & 0,627 & 0,066 & $\downarrow-0,561$ \\
\hline Лимфоциты & 1,26 & 1,188 & $\downarrow-0,075$ \\
\hline Моноциты & 2,87 & 3,30 & $\uparrow+0,433$ \\
\hline CD 3 & 0,706 & 0,581 & $\downarrow-0,125$ \\
\hline CD 4 & 0,681 & 0,625 & $\downarrow-0,056$ \\
\hline CD 8 & 1,21 & 1,50 & $\uparrow+0,291$ \\
\hline CD 16 & 0,607 & 0,393 & $\downarrow-0,214$ \\
\hline $\mathrm{CD} 20$ & 0,927 & 0,852 & $\downarrow-0,076$ \\
\hline ИРИ (CD 4 / CD 8) & 0,560 & 0,587 & $\uparrow+0,027 ; p>0,05$ \\
\hline CD 25 & 0,400 & 0,533 & $\uparrow+0,133$ \\
\hline CD 95 & 0,857 & 0,714 & $\downarrow-0,143$ \\
\hline HLA DR & 0,668 & 0,432 & $\downarrow-0,236$ \\
\hline IL-1 $\beta$ & 4,74 & 5,152 & $\uparrow+0,416$ \\
\hline IL-2 & 2,61 & 2,16 & $\downarrow-0,456$ \\
\hline IL-4 & 3,27 & 2,61 & $\downarrow-0,665$ \\
\hline IL-6 & 8,65 & 12,7 & $\uparrow+4,05$ \\
\hline IL-8 & 5,16 & 6,26 & $\uparrow+1,10$ \\
\hline IL-10 & 17,4 & 13,4 & $\downarrow-3,96$ \\
\hline TNF- $\alpha$ & 4,40 & 6,24 & $\uparrow+1,84$ \\
\hline $\operatorname{Ig} \mathrm{A}$ & 1,04 & 0,926 & $\downarrow-0,109$ \\
\hline Ig M & 0,943 & 0,733 & $\downarrow-0,210$ \\
\hline $\operatorname{Ig} G$ & 0,716 & 0,524 & $\downarrow-0,192$ \\
\hline ФИ & 0,882 & 0,868 & $\downarrow-0,014 ; p>0,05$ \\
\hline$\Phi Ч$ & 0,985 & 0,746 & $\downarrow-0,239$ \\
\hline
\end{tabular}

особого внимания при прогнозировании исхода и выборе тактики лечения таких пострадавших. Второе, эти показатели являются жёсткими константами организма (что маловероятно) и их несущественные отклонения компенсируются комплексом иных показателей организма. Второе утверждение применимо для производных показателей, например, таких как артериальное давление или минутной объём крови, которые мы разбирали в нашей предыдущей статье. В данном случае, это, скорее всего, является случайной находкой исследования. Чего нельзя сказать о показателях сегментоядерного и палочкоядерного нейтрофилёза (выше на 225\% и $263 \%$ соответственно, p<0,001) и запредельной гиперцитокинемии по уровню IL-6 (выше на $405 \%, \mathrm{p}<0,001)$. Данные результаты можно рассматривать в качестве начала развития синдрома системного воспалительного ответа (ССВО, system inflammatory response syndrome, SIRS). Что может иметь существенное прогностическое и терапевтическое значение.

Как мы видим из результатов проведенного метаанализа, существуют некоторые различия 


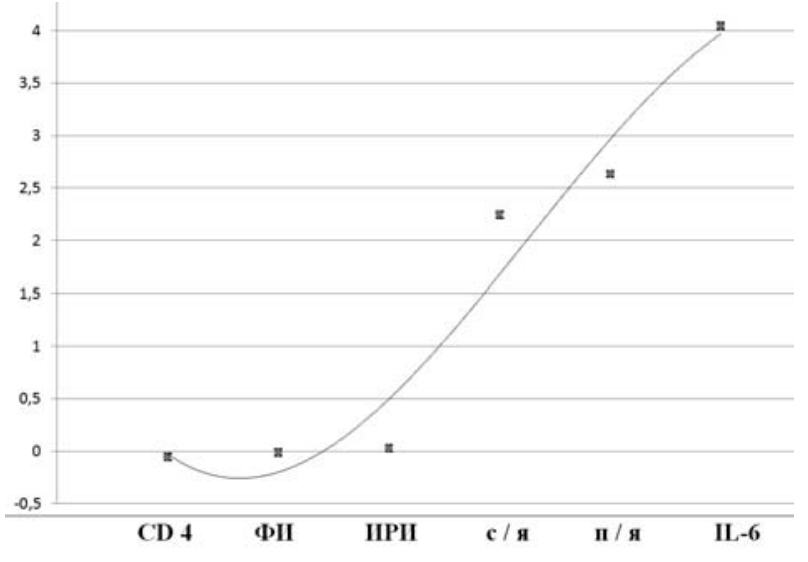

Рис. 3. Разница обобщённых иммунологических показателей пострадавших с неблагоприятным исходом травмы от пострадавших с благоприятным исходом (принята за ноль)

по показателям неблагоприятного исхода у животных, полученные в эксперименте и данных у пострадавших людей. Таким образом, результаты, которые получены на мелких лабораторных животных (крысах) следует с большой осторожностью переносить на реальные обстоятельства развития травматической болезни у людей. Это возможно объяснить различными патогенетическими механизмами нейроиммуноэндокринной регуляции. Что и явилось предметом наших последующих исследований.

\section{З А К Л Ю Е Н И Е}

Подводя итог метаанализа иммунологических и микробиологических показателей при всех видах экспериментальных травм, можно выделить три показателя, предположительно, наименее влияющих на исход травмы, это фагоцитарное число $(-0,056), \operatorname{Ig} \mathrm{M}(-0,033)$ и IL-4
$(+0,468), \mathrm{p}<0,001$. И можно констатировать четыре показателя, вероятно, наиболее влияющих на исход травмы, это палочкоядерный нейтрофилёз (выше на 527\%) и запредельная гиперцитокинемия по уровню TNF- $\alpha$ (выше на 851\%), IL-6 (выше на 1 300\%) и IL-8 (выше на 1 560\%), $\mathrm{p}<0,001$.

У пострадавших с неблагоприятным исходом травмы отклонения иммунологических показателей статистически значимо (p<0,001) были более выраженными по показателям сегментоядерного и палочкоядерного нейтрофилёза (выше на 225\% и 263\% соответственно) и запредельной гиперцитокинемии по уровню IL-6 (выше на 405\%) и наименее выраженными по показателям CD $4(-0,056 ;$ p $<0,001)$, фагоцитарного индекса $(-0,014 ; \mathrm{p}>0,05)$ и иммунорегуляторного индекса (+ 0,027, p>0,05) по сравнению с группой пациентов с благоприятным исходом.

Полученные результаты метаанализа убедительно говорят, что данные, которые получены на мелких лабораторных животных (крысах) следует с большой осторожностью переносить на реальные обстоятельства развития травматической болезни у людей. Это возможно объяснить различными патогенетическими механизмами нейроиммуноэндокринной регуляции.

Перспективы для дальнейших исследований

В результате проведённого метаанализа наметилась следующая научная задача: провести метаанализ нейроиммунноэндокриных показателей у животных в эксперименте и у пациентов с травматической болезнью, для уточнения ключевых звеньев её патогенеза, которые в последующем смогут явиться прогностическими критериями и целями для таргетной терапии, дать заключение о возможности перенесения экспериментальных данных на организм человека.

\section{Ю.И. Стрельченко, В.Н. Ельский}

ГОО ВПО «Донецкий национальный медицинский университет имени М. Горького», Донецк

\section{МЕТААНАЛИЗ ИММУНОЛОГИЧЕСКИХ И МИКРОБИОЛОГИЧЕСКИХ ПОКАЗАТЕЛЕЙ ПРИ ТРАВМАТИЧЕСКОЙ БОЛЕЗНИ}

Цель исследования. Провести метаанализ иммунологических и микробиологических показателей при травматической болезни, полученных на кафедре патофизиологии для уточнения ключевых звеньев её патогенеза, которые в последующем смогут явиться прогностическими критериями и целями для таргетной терапии, дать заключение о возможности перенесения экспериментальных данных на организм человека. Материал и методы. Был проанализирован обширный экспериментальный и отчасти клинический материал по травматической болезни за последние 40 лет, накопившийся на кафедре патологиче- ской физиологии ГОО ВПО ДОННМУ ИМ. М. ГОРКЬОГО. Результаты и выводы. У экспериментальных животных можно выделить три показателя, предположительно, наименее влияющих на исход травмы, это фагоцитарное число, Ig M и IL-4. И можно констатировать четыре показателя, вероятно, наиболее влияющих на исход травмы, это палочкоядерный нейтрофилёз и запредельная гиперцитокинемия по уровню TNF- $\alpha$, IL-6 и IL-8. У пострадавших с неблагоприятным исходом травмы отклонения иммунологических показателей статистически значимо были более выраженными по показателям сегментоядерного и па- 
лочкоядерного нейтрофилёза и запредельной гиперцитокинемии по уровню IL-6 и наименее выраженными по показателям CD 4, фагоцитарного индекса и иммунорегуляторного индекса по сравнению с группой пациентов с благоприятным исходом. Полученные результаты метаанализа убедительно говорят, что данные, которые получены на мелких лабораторных животных (крысах) следует с большой осторожностью переносить на реальные обстоятельства развития травматической болезни у людей. Это возмож- но объяснить различными патогенетическими механизмами нейроиммуноэндокринной регуляции. Перспективы для дальнейших исследований. В результате проведённого метаанализа наметилась следующая научная задача: провести метаанализ нейроиммунноэндокриных показателей у животных в эксперименте и у пациентов с травматической болезнью.

Ключевые слова: метаанализ, травматическая болезнь, иммунология, микробиология.

\section{I. Strelchenko, V. N. Jelski}

SEI HPE «M. Gorky Donetsk National Medical University», Donetsk

\section{META-ANALYSIS OF IMMUNOLOGICAL AND MICROBIOLOGICAL INDICATORS IN TRAUMATIC DISEASE}

The purpose of the study. To conduct the meta-analysis of immunological and microbiological parameters for traumatic disease obtained at the Department of Pathophysiology to clarify the key links of its pathogenesis, which subsequently can become prognostic criteria and goals for targeted therapy, to give an opinion on the possibility of transferring experimental data to the human body. The material and methods. The extensive experimental and partly clinical material on traumatic disease over the past 40 years was analyzed, which accumulated at the Department of Pathological Physiology of the M. Gorky DNMU.

The results and conclusions. Three indicators can be distinguished in experimental animals, presumably the least affecting the outcome of the injury, are the phagocytic number, Ig M and IL-4. In addition, we can state four indicators, probably the most influencing the outcome of the injury are stab neutrophilia and transcendental hypercytokinemia in terms of TNF- $\alpha$, IL- 6 and IL-8. In patients with an unfavorable outcome of injury, deviations of immunological parameters were statistically significantly more pronounced in terms of segmented and stab neutrophilia and prohibitive hypercytokinemia in terms of IL- 6 and least pronounced in terms of CD 4, phagocytic index and immunoregulatory index compared with a group of patients with a favorable outcome. The results of meta-analysis convincingly say that the data obtained on small laboratory animals (rats) should be transferred with great care to the real circumstances of the development of a traumatic disease in humans. This can be explained by various pathogenetic mechanisms of neuroimmunoendocrine regulation.

The prospects for further research. As a result of the meta-analysis, the following scientific task was outlined: to conduct a meta-analysis of neuroimmune endocrine parameters in animals in the experiment and in patients with traumatic disease.

Key words: meta-analysis, traumatic disease, immunology, microbiology.

\section{ЛИТЕРАТУРА}

1. https://www.who.int/violence_injury_prevention/ru/

2. Городник Г.А. Ельский В.Н., Смирнова Н.Н., Стрельченко Ю.И., Онищенко Е.В. Патогенез боевой травмы (обзор литературных данных). Архив клинической и экспериментальной медицины. 2015; 24 (1): 51-57.

3. http://statistica.ru/local-portals/medicine/meta-analiz/

4. https://statanaliz.info/statistica/opisanie-dannyx/dispersiya-i-standartnaya-oshibka-doli/

\section{REFERENCES}

1.https://www.who.int/violence_injury_prevention/ru/

2. Gorodnik G.A. El'skii V.N., Smirnova N.N., Strel'chenko Yu.I., Onishchenko E.V.. Patogenez boevoi travmy (obzor literaturnykh dannykh) [Pathogenesis of military injury (literature review)].Arkhiv klinicheskoi i eksperimental'noi meditsiny. 2015; 24 (1): 51-57 (in Russian).

3. http://statistica.ru/local-portals/medicine/meta-analiz/

4. https://statanaliz.info/statistica/opisanie-dannyx/dispersiya-i-standartnaya-oshibka-doli/ 